\title{
EL CUERPO, LA AUTONOMÍA Y LAS PROFESIONES SANITARIAS. DEBATE PERMANENTE
}

\author{
Fernando Lolas Stepke
}

Los textos de esta edición de Acta Bioethica, con ser diversos, proponen una lectura unificadora. Ella se basa en la ya tradicional disputa sobre la propiedad del cuerpo humano. "Soy" un cuerpo y "tengo" un cuerpo, decía Gabriel Marcel. La corporalidad es un atributo definitorio de la persona humana en cuanto representación para los demás y es corporeidad subjetiva en cuanto campo de resonancias de afectos, placeres, dolores y necesidades.

En la lengua alemana se distingue entre "Leib", el cuerpo animado o vivo, y "Körper", como el basamento material que se aprecia en el cadáver. Uno es vitalidad, el otro mecanismo. El Leib es campo de intencionalidades y disposiciones. El Körper es un objeto entre objetos.

No solamente en el plano de las donaciones de órganos y la necesaria dilucidación que exige la técnica de los trasplantes es relevante el tema de la propiedad del propio cuerpo. También la polémica sobre el aborto gira en buena medida sobre si la mujer embarazada es dueña de su cuerpo. La extensión de la idea a ser dueña de la vida que se ha concebido - distinta del cuerpo propio- merece sin duda un examen, toda vez que la concepción y la gestación introducen algo cualitativamente distinto a un tumor o un órgano cualquiera. Obviamente, en este caso el debate gira en torno al comienzo de la vida que propiamente puede llamarse humana.

La autonomía es concepto polisémico que suele asociarse a la libertad. También la libertad es compleja, toda vez que puede haberla de disponer de opciones o de propiedad de hacer lo que se desea con lo que es propio. Algunas concepciones clásicas de la autonomía destacan que ella es legítima en la medida en que se ajusta a un canon de racionalidad que sería inherente a la naturaleza humana. Libre elección puede no significar sencillamente libre disposición de los bienes propios.

Como estos temas se encuentran relacionados con la práctica de las profesiones sanitarias no extraña que quienes las ejercen enfrenten a diario perplejidades y dilemas. En la mayoría de los casos, la propia conciencia debe confrontarse a las regulaciones socialmente aceptadas, ya sea por la ley, la tradición o la costumbre. Ello plantea la ya frecuente pregunta sobre si hay legislaciones más "avanzadas" que otras porque permiten actitudes y acciones que históricamente estaban vedadas a las personas.

Las discusiones no terminan adoptando posturas. Siempre habrá casos limítrofes. Es así que todo dilema ético se construye sobre el fundamento de un choque de principios. Por ejemplo, entre la autonomía individual y la beneficencia o la justicia. Cuando la autonomía se extiende de las personas naturales a las jurídicas (o morales) se obtiene un panorama que exige y exigirá permanente análisis en el contexto dialógico que se juzga constitutivo de la racionalidad bioética. Y como los contextos históricos cambian, a tenor de la factibilidad técnica de las intervenciones sobre el cuerpo y la mente, es natural que los debates y las discrepancias exijan permanente examen. En ello radica probablemente el valor de la palabra no escrita y de la deliberación moral que anteceden y siguen a la dictación de leyes y reglamentos.

La cosificación del cuerpo animado plantea además una pregunta obvia. ¿Es el cuerpo siempre la misma cosa? ¿Se dispone de él igual en todas las edades? ¿Es su propiedad comparable a la de un objeto inanimado? Basta pensar en los achaques irreversibles de la enfermedad o la edad para percibir que

\footnotetext{
${ }^{1}$ Director "Acta Bioethica". Centro Interdisciplinario de Estudios en Bioética, Universidad de Chile, Chile Correspondencia: flolas@uchile.cl
} 
el cuerpo propio puede volver súbitamente "extraño" y dejar de ser ese particular constituyente de la propia identidad, siempre asociada a un querer, a un poder y a un disponer.

También con respecto a la disposición sobre un cuerpo ajeno la reflexión es desafiante. La posibilidad de terminar la vida corporal de otro ser humano incapaz de decidir por sí mismo se plantea reiteradamente cuando se discute sobre si los menores de edad o las personas privadas de conciencia pueden someterse a la terminación de su vida por decisión ajena. La idea del "mejor interés" suele no coincidir con la "decisión vicariante o sustitutiva" de quienes tienen imperio sobre el vivir y morir ajenos. $\mathrm{Mu}$ chos debates sobre la mal llamada eutanasia activa, el suicidio asistido o la eutanasia pasiva rozan estas cuestiones. Obviamente, aquí la idea central debiera ser la "ortotanasia", la muerte correcta, ajustada a la vital trayectoria de quien muere y a lo que constituye su personal narrativa e insustituible identidad.

Para los lectores de Acta Bioethica valga como consideración central que esta publicación es un foro neutral, pero no indiferente, sobre dilemas que exigen preguntas y respuestas. Al "ser" de las cosas como son se agrega siempre el "deber ser" de la norma moral (propia o ajena) y el "tener que ser" de las vocaciones personales ineludibles. Difícilmente podría hacerse de estas reflexiones una artesanía mecánica. Aparte de métodos apropiados, tales cuestiones demandan un modo adecuado de plantearlas, una intuición empática y la disposición a desentrañar el significado de los actos humanos.

Que estos sean temas que demandan análisis y reflexión, y por ende investigación metódicamente fundada, no significa que deban eliminarse el momento comprensivo y el momento interpretativo que las disciplinas humanas introducen en la práctica de las profesiones sanitarias. Éstas siempre conjugan un saber técnico y una prudencia reflexiva que conforman aquella ecuanimidad que Sir William Osler juzgaba esenciales en el cuidado profesional de la salud. 